\title{
Toxic Epidermal Necrolysis and its impact on Physiotherapy Management: a Case Report
}

\begin{abstract}
The purpose of this paper is to report on the modified physiotherapy intervention for toxic epidermal necrolysis (TEN) in a 31 year old pregnant human immunodeficiency virus (HIV) seropositive woman on antiretroviral therapy. Physiotherapy intervention consisted of nebulisation and the active cycle of breathing technique in order to clear secretions. To restore lung volumes, the active cycle of breathing technique was utilized in addition to positive expiratory pressure, incentive spirometry and positioning. Passive and active exercises and stretches were employed to maintain and regain range of motion in affected limbs. Following intervention, positive changes were noted in outcome measures such as secretion clearance, breath sounds and general function. It is concluded that physiotherapy intervention has a role to play in the rehabilitation of patients with TEN.
\end{abstract}

KEY WORDS: STEVENS-JOHNSON SYNDROME, TOXIC EPIDERMAL NECROLYSIS, ANTIRETROVIRAL THERAPY, PHYSIOTHERAPY

\section{Introduction}

Stevens-Johnson syndrome (SJS) and toxic epidermal necrolysis (TEN) are severe cutaneous disorders resulting from adverse reactions to drugs. StevensJohnson syndrome was first described in 1922 and TEN in 1948. The annual incidence of these conditions range between 0.4 to 7 per million population (Khalili \& Bahna 2006). These conditions are characterized by detachment of the epidermis and erosions of mucous membranes, fever, malaise and vesiculobullous eruptions (Fagot et al 2001; Khalili \& Bahna 2006; Mockenhaupt et al 2007). Both conditions occur as a result of rapid onset of keratinocyte apoptosis, the consequence of which is the separation of the epidermis from the dermis (French et al 2006). The difference between the two conditions is the extent of skin detachment being less than $10 \%$ in SJS and more than $30 \%$ in TEN. The mortality rate for SJS is $1-5 \%$ and $25-35 \%$ in TEN (Khalili

Correspondence to:

Jenny Schneiderman

PO Box 235 Morningside 2057

Email: schn@iafrica.com
\& Bahna 2006). Mortality rate increases up to $23 \%$ when SJS occurs in the presence of HIV seropositivity (Dukes et al 1992; Kuaban et al 1997). Mortality rate in TEN in the presence of HIV seropositivity is unknown. Drugs most frequently associated with SJS and TEN are antiretrovirals, antibacterial sulfonamides, non-steroidal anti-inflammatory drugs and anti-convulsants (French et al 2006; Khalili \& Bahna 2006).

Highly active antiretroviral therapy (HAART) has increased survival in patients with human immunodeficiency virus (HIV) (Panos et al 2008). However, HAART is toxic (Mockenhaupt et al 2007; Davidson et al 2010). The increased distribution of antiretroviral drugs to the South African population has resulted in an increased presentation of patients with adverse effects from these drugs to our hospitals. As the population of patients who survive HIV grows, it has become important to recognize the adverse cutaneous reactions from these therapies (Kong \& Myers 2005). Mockenhaupt et al (2007) noted that Nevirapine has replaced anti-infective sulfonamides as the leading cause of severe skin reactions in HIV infected patients. Nevirapine is a non-nucleoside reverse transcriptase inhibitor and works by inducing a conformational change to the structure of the reverse transcriptase enzyme of HIV thus preventing the conversion of RNA to DNA (Kong \& Myers 2005; Luther \& Glesby 2007). In their study, Luther and Glesby (2007) observed that Nevirapine caused SJS with a frequency of $0.3 \%$. Furthermore, Nevirapineassociated rash is more common in patients with higher baseline $\mathrm{CD}_{4}$ cell counts with a possibility of women being more susceptible than men. Skin reactions are the most common reason for patients to discontinue Nevirapinebased therapy. Fagot et al (2001) conducted a case control study in Europe in order to ascertain the relationship between Nevirapine, SJS and TEN. They found that $83 \%$ of HIV positive patients who presented with SJS and TEN had had exposure to Nevirapine. Both SJS and TEN are life-threatening diseases and outcome is favored by early recognition and withdrawal of causative drugs no later than the day when blisters of erosion appear (Wolf et al 2005). No information is currently available on the prevalence and morbidity/mortality of SJS and TEN in HIV seropositive patients in South Africa. 


\section{Case History}

A 31 year old female was admitted to a government hospital in the Johannesburg region on 27/02/2009 with skin blisters. The patient was diagnosed with HIV on 19/01/2009 and commenced Nevirapine therapy on $20 / 02 / 2009$. The patient was 37 weeks pregnant at the time of admission. She thought that the baby was causing this reaction and thus brought herself to the hospital. She was diagnosed with TEN and presented with $80 \%$ of body surface area involvement. The patient was initially admitted to the ward for observation and investigation. A caesarean section was subsequently performed and a baby boy was born and cared for in the paediatric ward. The patient was transferred to ICU for observation after the surgery. The medical team requested physiotherapy intervention four days after admission to ICU when the patient's condition stabilised.

\section{Physical Examination}

Initial assessment of her chest x-ray (taken post caesarean section) revealed opacification over the right basal lung segments. Auscultation of her chest revealed coarse crepitations and decreased breath sounds in the left and right posterior upper and posterior basal segments. Chest expansion was visibly decreased over the basal lung segments (anterior and posterior) but couldn't be accurately measured due to the presence of bandages over the thorax. Breathing was shallow with an apical pattern [Respiratory rate $(\mathrm{RR})=16$ breaths/minute $(\mathrm{b} / \mathrm{min})]$. The patient had a productive cough and expectorated small amounts of purulent (thick yellow) sputum. Cough effectiveness was limited by pain from the thoracic blisters as well as from the caesarean section. Analysis of her blood gas results showed a mixed primary respiratory and metabolic alkalosis. See Table 1 for arterial blood gas results. The arterial line was removed in the high care unit. The patient was oxygenated (not humidified) using nasal cannulae. See Table 2 for full blood count results. The patient presented with anaemia and low platelets due to blood loss. High C-reactive protein was indicative of inflammation.
Musculoskeletal assessment revealed decreased range of motion (ROM) in elbow flexion, shoulder elevation, shoulder abduction and hip flexion due to pain and the presence of dressings. See Table 3 for ROM measurements for selected joints of both the right and left limbs. The patient presented with fair muscle strength in both upper and lower limbs on all movements assessed. The patient's functional activities were limited as she was able to roll in bed with moderate assistance and come up

into sitting over the edge of the bed with maximal assistance from one therapist. The patient could not feed herself nor was she able to get a glass of water to her lips due to reduced ROM in her upper limbs from pain and restriction of the bandages.

The patient's medication consisted of: Aldactone (diuretic), Acyclovir (antiviral), Pantoloc (proton pump inhibitor), Panado (analgesia), Clexane (anti-coagulant), Fluconazole (anti-fungal antibiotic) and Morphine (analgesia).

Table 1: Arterial blood gas results

\begin{tabular}{|l|l|l|}
\hline & $\begin{array}{l}\text { Day 4 (ICU) on nasal } \\
\text { cannulae 10 I/min }\end{array}$ & $\begin{array}{l}\text { Day 1 (HC) on nasal } \\
\text { cannulae 2 I/min }\end{array}$ \\
\hline $\mathrm{pH}$ & $7.54(\uparrow)$ & $7.54(\downarrow)$ \\
\hline $\mathrm{PaCO}_{2}$ & $33.7 \mathrm{mmHg}(\downarrow)$ & $31.1 \mathrm{mmHg}(\downarrow)$ \\
\hline $\mathrm{HCO}_{3}$ & $29.9 \mathrm{mmol} / \mathrm{L}(\uparrow)$ & $29.8 \mathrm{mmol} / \mathrm{L}(\uparrow)$ \\
\hline $\mathrm{BE}$ & $5.3(\uparrow)$ & $4.6(\uparrow)$ \\
\hline $\mathrm{PaO}_{2}$ & $112.9 \mathrm{mmHg}$ & $112.4 \mathrm{mmHg}(\uparrow)$ \\
\hline $\mathrm{SaO}_{2}$ & $97.8 \%$ & $99 \%$ \\
\hline
\end{tabular}

BE: Base Excess, mmHg: millimeters of mercury, $\mathrm{PaCO}_{2}$ : partial pressure of carbon dioxide in arterial blood, $\mathrm{HCO}_{3}$ : bicarbonate, $\mathrm{PaO}_{2}$ : partial pressure of oxygen in arterial blood, $\mathrm{SaO}_{2}$ : saturation of oxygen in arterial blood, $\mathrm{HC}$ : high care

Table 2: Full blood count results

\begin{tabular}{|l|l|l|l|}
\hline & Day 4 (ICU) & Day $\mathbf{2}(\mathbf{H C})$ & Day 4 (HC) \\
\hline $\mathrm{Hb}$ & $8.0 \mathrm{~g} / \mathrm{dL}(\downarrow)$ & $9.7 \mathrm{~g} / \mathrm{dL}(\downarrow)$ & $7.5 \mathrm{~g} / \mathrm{dL}(\downarrow)$ \\
\hline $\mathrm{WCC}$ & $5.0 \times 10^{9} / \mathrm{L}$ & $2.7 \times 10^{9} / \mathrm{L}(\downarrow)$ & $18 \times 10^{9} / \mathrm{L}(\uparrow)$ \\
\hline Platelets & $65 \times 10^{9} / \mathrm{L}(\downarrow)$ & $73 \times 10^{9} / \mathrm{L}(\downarrow)$ & $85 \times 10^{9} / \mathrm{L}(\downarrow)$ \\
\hline $\mathrm{Na}^{+}$ & $163 \mathrm{mmol} / \mathrm{l}(\uparrow)$ & $146 \mathrm{mmol} / \mathrm{L}$ & $145 \mathrm{mmol} / \mathrm{L}$ \\
\hline $\mathrm{K}^{+}$ & $4.3 \mathrm{mmol} / \mathrm{l}$ & $4.4 \mathrm{mmol} / \mathrm{L}$ & $4.2 \mathrm{mmol} / \mathrm{L}$ \\
\hline $\mathrm{CRP}$ & $234 \mathrm{mg} / \mathrm{L}(\uparrow)$ & $230 \mathrm{mg} / \mathrm{L}(\uparrow)$ & $283 \mathrm{mg} / \mathrm{L}(\uparrow)$ \\
\hline
\end{tabular}

HC: high care, ICU: intensive care unit, Hb: Haemoglobin, WCC: White cell count, Na: Sodium, $K^{+}$: Potassium, CRP: C-reactive protein

Table 3: Range of motion of selected peripheral joints at initial assessment in ICU

\begin{tabular}{|l|l|l|}
\hline & Active ROM & Passive ROM \\
\hline Elbow Flexion & $0-80^{\circ}$ & $0-92^{\circ}$ \\
\hline Shoulder Elevation & $0-85^{\circ}$ & $0-120^{\circ}$ \\
\hline Shoulder Abduction & $0-90^{\circ}$ & $0-110^{\circ}$ \\
\hline Hip Flexion & $0-90^{\circ}$ & $0-100^{\circ}$ \\
\hline
\end{tabular}




\section{Physiotherapy Intervention}

The goals of physiotherapy intervention in patient care in the ICU generally include restoration/maintenance of lung volumes and lung compliance, improvement of gas exchange at alveolarcapillary level, enhancement of secretion clearance, reduction in work of breathing and restoration of function (Pryor and Prasad 2008). The following main problems were identified in this patient after the initial assessment: apical shallow breathing pattern; decreased breath sounds as well as coarse crepitations indicative of secretion retention in the left and right posterior upper and posterior basal segments; decreased chest expansion; weak cough effort; decreased ROM in elbow, shoulder and hip joints in view of pain; decreased functional abilities and demotivation and depression.

\section{a) Retention of excessive secretions}

Chest physiotherapy was applied to clear pulmonary secretions as described below. The patient was nebulised in a seated position with $5 \mathrm{ml} 0.9 \% \mathrm{NaCl}$ solution to humidify the airways and enhance mobility of secretions. Active cycle of breathing technique (ACBT) was performed and emphasis was placed on the forced expiratory technique to mobilise secretions to the proximal airways (Pryor and Prasad 2008). The upright seated position was incorporated to facilitate improved huffing and coughing manoeuvers (Badr, Elkins \& Ellis 2002). The patient experienced pain both from the TEN as well as her caesarean section incision and was thus taught to cough with wound support. She was encouraged to cough and managed to expectorate a large amount of yellow-coloured secretions. These treatment options were selected instead of manual techniques due to the patient's low platelet count and subjective complaint of discomfort or pain (Hough 2001; Pryor and Prasad 2002; Harden 2004).

\section{b) Decreased lung volumes and chest expansion}

The patient was placed in a seated position with the aim of enhancing ventilation/perfusion matching and breathing control was performed to encourage diaphragmatic breathing. The patient showed no signs of respiratory distress during position changes. Active cycle of breathing was applied with emphasis on the thoracic expansion components namely the three-second inspiratory hold as well as inspiratory sniffs, to enhance ventilation in the basal segments. Two to three cycles of ACBT were performed during a treatment session. Oscillating positive expiratory pressure (PEP) in the form of a blow bottle (filled with $10 \mathrm{~cm}$ of water) was applied to further increase ventilation. The patient was advised to perform treatment with the blow bottle 10 times per hour, three to five times per day. Incentive spirometry (IS) combined with lower chest wall breathing was also added to her treatment to encourage larger inspiratory tidal volume breaths (Pryor \& Prasad 2008). The patient was advised to use the IS 10 times per hour, three to five times per day. On auscultation the patient's breath sounds in the posterior basal lung segments did improve over consecutive days.

\section{c) Decreased function}

Functional activities included daily progression from bed activities to sitting over the edge of the bed to mobilising into a chair (Gosselink et al 2008). Care was taken to respect the patient's pain levels. Low $\mathrm{Hb}$ levels and subjective complaints of fatigue were the other precautions that were observed during treatment sessions. Her vital signs were monitored with special attention to oxygen saturation as well as any signs of respiratory distress such as nasal flaring, an increased RR and changes in breathing pattern. Furthermore, care was taken not to make the activities too strenuous for the patient. At the end of the treatment session, the patient was positioned in Fowler's position.

\section{d) Decreased joint range of motion}

In order to regain ROM and prevent contractures, passive movements and stretches were applied to the patient's limbs again being sensitive to the patient's pain levels. Before the commencement of each physiotherapy session, an additional dosage of the prescribed analgesia was administered by the nursing sister. Activities progressed daily from passive movements to active assisted to active movements and finally to functional exercises. The patient received physiotherapy treatment twice daily.

\section{e) Psychosocial support}

Due to the nature of the patient's condition (pain and cosmetic disfigurement), the patient was very depressed and demotivated. Thus, the physiotherapist's role extended to giving emotional support, education about the condition and encouragement during physical activities.

\section{Outcomes}

Two days after initial physiotherapy assessment, the patient's condition had stabilised and the patient was discharged from ICU and moved to the high care ward. On re-assessment the patient's condition continued to improve as auscultation revealed improved breath sounds in the posterior basal lung segments and intermittent coarse crepitations were now limited only to these segments. She was able to expectorate moderate amounts of secretions effectively. Oxygen therapy was discontinued on the third day in high care. Her RR fluctuated between 12 and $20 \mathrm{~b} / \mathrm{min}$ on room air and no signs of respiratory distress were observed. There was a reduction in her hesitancy to mobilise and by the fourth day in high care, the patient required only minimal assistance to roll in bed and mobilise into a chair. Improvements in both active and passive ROM were observed. Unfortunately, the patient's condition suddenly deteriorated during the evening of day four in high care and she passed away due to unexplained medical complications.

\section{Discussion}

The World Health Organization estimated the number of people living with HIV at the end of 2006 to be 39.5 million worldwide. Of that, $64 \%$ live in sub-Saharan Africa (South African Department of Health, 2007). The South African Department of Health $(\mathrm{DoH})$ reported that at the end of 2006, 5.4 million people were living with HIV or AIDS. Approximately $230000 \mathrm{HIV}$ infected individuals were receiving antiretroviral treatment in 2006 (South African Department of Health, 2007). The strategic plan laid out by the DoH called for a continued increase in the number of adults to commence antiretroviral therapy so that by 2011, 4200000 people $(80 \%)$ would be on HAART (South African Department of Health, 
2007). With the expected increase in distribution of antiretroviral therapy, the health professional might expect an increased occurrence of patients presenting with adverse effects as a result of such medication. The mortality rate of SJS in the presence of HIV seropositivity has increased to $23 \%$ as discussed previously and that of TEN is still unknown. The aim of this case report was to outline the modified physiotherapy treatment plan used for a patient with TEN during the acute phase of her illness. Manual chest therapy techniques were not used to enhance secretion clearance as SJS and TEN lead to blister formation on the skin which is likened to a second or third degree burn when the blister opens, resulting in significant patient discomfort. Secondly, manual chest physiotherapy techniques were not implemented due to the patient presenting with a low platelet count (Hough 2001; Pryor and Prasad 2002; Harden 2004). In addition to this, SJS and TEN lead to erosion of mucus membranes of organs inside the body and for this reason suctioning with a catheter to clear airway secretions was not employed. Fortunately, the patient was awake and alert and was able to expectorate her secretions adequately. Therefore indirect secretion clearance techniques such as nebulisation with $0.9 \% \mathrm{NaCl}$, ACBT, cough and positioning as well as techniques to improve air entry consisting of PEP, IS and mobilisation proved to be beneficial in decreasing her secretion retention and improving her breath sounds. The detrimental effects of immobility on the human body are well documented (Convertino, Bloomfield \& Greenleaf 1997; Gosselink et al 2008) and these include secretion retention and atelectasis, deconditioning of the musculoskeletal system and loss of hydrostatic pressure in the cardiovascular system. Moving from a supine position to that of a head up tilt or standing was previously shown to increase functional residual capacity (FRC) and aided in restoration of lung volumes in healthy subjects as well as in patients after abdominal surgery (Zafiropoulos, Alison \& McCarren 2004; Chang et al 2005; Lumb 2005; Frownfelter \& Dean 2006; Pierce 2007). Mobilisation out of bed, together with passive and active exercises was therefore deemed to be important components of this patient's management in ICU and high care. The authors can only speculate on the cause of death in this case as both the physician and dermatologist agreed that her condition had stabilised and that the wounds were healing well on the fourth day of her stay in high care. This patient was an illegal immigrant and therefore an autopsy was not performed.

\section{Conclusion}

The incidence of adverse effects of antiretroviral therapy has the potential to grow considerably due to the increased accessibility of therapy to the relevant patient population. Patients with SJS and TEN may therefore present more frequently to our ICUs and hospitals. In this case, physiotherapy was aimed at rehabilitation and the patient benefited from the intervention during her stay in ICU and high care. Physiotherapists should be informed about the complications of HAART and on how to modify treatment techniques so as not to add to the discomfort that the patient experiences during their illness.

\section{References}

Badr C, Elkins MR, Ellis ER 2002 The effect of body position on maximal expiratory pressure and flow. Australian Journal of Physiotherapy 48: 95-102

Chang AT, Boots RJ, Brown MG, Paratz JD, Hodges PW 2005 Ventilatory changes following head-up tilt and standing in healthy subjects. European Journal of Applied Physiology 95: 409-417

Convertino A, Bloomfield SA \& Greenleaf JE 1997 An overview of the issues: physiological effects of bed rest and restricted physical activity. Medical Science and Sport Exercise 29 (2): 187-190

Davidson I, Beardsell H, Smith B, Mandalia S, Bower M, Gazzard B, Nelson M, Stebbing J 2010 The frequency and reasons for antiretroviral switching with specific antiretroviral associations: the SWITCH study. Antiviral Research 85 [Epub ahead of print]

Department of Health 2007 HIV and AIDS and STI Strategic Plan for South Africa 2007-2011. Retrieved 02/04/2009 http://www.doh.gov.za/docs/ HIVAIDS-progressrep.html.

Dukes CS, Sugarman J, Ceqielski JP, Lallinger GJ, Mwakyusa DH 1992 Severe cutaneous hypersensitivity reactions during treatment of tuberculosis in patients with HIV infection in Tanzania. Tropical and Geographical Medicine 44(4): 308 - 311

Fagot JP, Mockenhaupt M, Bouwes-Bavick JN, Naldi L, Viboud C, Roujeau JC 2001 Nevirapine and the risk of Stevens-Johnson syndrome or toxic epidermal necrolysis._AIDS 15: 1843 - 1848
French LE 2006 Toxic Epidermal Necrolysis and Stevens-Johnson Syndrome: Our Current Understanding. Allergology International 55: 9 - 16

Frownfelter D, Dean E 2006 Cardiovascular and pulmonary physical therapy: evidence and practice, $4^{\text {th }}$ edn. pp. $307-321$. Elsevier Publishers, Toronto

Gosselink R, Bott J, Johnson M, Dean E, Nava S, Norrenberg M, Schonhofer B, Stiller K, Van de Leur H, Vincent JL 2008 Physiotherapy for adult patients with critical illness: recommendations of the European Respiratory Society and European Society of Intensive Care Medicine task force of physiotherapy for critically ill patients. Intensive Care Medicine 34: 1188 - 1199

Harden B 2004 Emergency physiotherapy: An on call survival guide. Pg 129. Churchill Livingstone, Edinburgh

Hough A 2001 Physiotherapy in respiratory care. An evidence-based approach to respiratory and cardiac management. $3^{\text {rd }}$ edn. pp 29. Nelson Thornes, Cheltenham

Khalili B, Bahna SL 2006 Pathogenesis and Recent Therapeutic Trends in Stevens-Johnson Syndrome and Toxic Epidermal Necrolysis. Annals of Allergy, Asthma and Immunology September 97: $272-281$

Kong HH, Myers SA 2005 Cutaneous effects of highly active antiretroviral therapy in HIV-infected patients. Dermatologic Therapy 18: $58-66$

Kuaban C, Bercion R, Koulla-Shiro S 1997 HIV seroprevalence rate and incidence of adverse skin reactions in adults with pulmonary tuberculosis receiving thiacetazone free anti-tuberculosis treatment in Yaounde, Cameroon. East African Medical Journal 74(8): $474-477$

Lumb A 2005 Nunn's applied respiratory physiology, $6^{\text {th }}$ edn. pp. $25-35$. Elsevier Publishers, Philadelphia

Luther J, Glesby MJ 2007 Dermatologic Adverse Effects of Antiretroviral Therapy._American Journal of Clinical Dermatology 8: 221 - 233

Mockenhaupt M, Viboud C, Dunant A, Naldi L, Halevy S, Bavick JNB, Sidoroff A, Schneck J, Roujeau JC, Flahault A 2007 Stevens-Johnson Syndrome and Toxic Epidermal Necrolysis: Assessment of Medication Risks with Emphasis on Recently Marketed Drugs. The EuroSCAR-Study. Journal of Investigative Dermatology 128: 35 - 44

Panos G, Samonis G, Alexiou VG, Kavarnou GA, Charatsis G, Falagas ME 2008 Mortality and morbidity of HIV infected patients receiving HAART: a cohort study. Current HIV Research 6: $257-260$

Pierce LNB 2007 Management of the mechanically ventilated patient, $2^{\text {nd }}$ edn. pp. $140-157$. Saunders Elsevier Publishers, Missouri

Pryor JA, Prasad SA 2002 Physiotherapy for respiratory and cardiovascular problems, $3^{\text {rd }}$ edn. pp. 363-364. Elsevier Publishers, Edinburgh

Pryor JA, Prasad SA 2008 Physiotherapy for respiratory and cardiovascular problems, $4^{\text {th }}$ edn. pp. 167, 270-304. Elsevier Publishers, Edinburgh

Wolf R, Orion E, Marcos B, Matz H 2005 Lifethreatening acute adverse drug reactions. Clinics in Dermatology 23: 171 - 181

Zafiropoulos B, Alison JA, McCarren B 2004 Physiological responses to the early mobilisation of the intubated, ventilated abdominal surgery patient. Australian Journal of Physiotherapy 50: 95 - 100 


\section{CPD Questions (Vol 66 no 2 - July 2010)}

1. Complete questionnaire and insert the correct answers in the spaces provided.

2. Ensure that you have included your full details as requested.

3. Only originalquestionnaires will beconsidered therefore please cut out and submit to SASP Head Office at: SASPCPD Questionnaire, P.OBox 752378, Gardenview, 2047 by 31 October 2010.
4. In order to capture your CPD points at the HPCSA your submission must beaccompanied by a proof of payment to the value of R20.00 (NO CASH/POSTAL ORDERS). Payments can be made by EFT to South African Society of Physiotherapy, FNB, Bedford Gardens, Branch Code: 252155, Account Number: 50371113363. Please use membership number/CPD Journal as reference.
Full Name:

Email:

\section{SASP Membership No.:}

HPCSA PT No.:

\section{QUESTIONS:}

1. Which factors play a role in problems with diabetes control in South Africa?

2. Why did the subjects in the intervention group relapse after 4 months?

3. Is there a need to develop academics in the skill for writing for publication?

a. Yes b. No

4. Do you agree that a scholarly activity such as writing for publication highlights the need to be open to, and accept constructive criticism or feedback through the process of peer review?

a. Yes b. No

5. What is reportedly a major reason for patient dissatisfaction with medical care for low back pain.

6. What percentage of subjects in this study expected their low back pain to recur?

7. State whether true or false

Weight bearing decreases spasticity

Weight bearing provides a sustained stretch to muscles

Grip strength in cerebral palsy children cannot be quantified

8. State whether true or false

Females were found to be at greater risk for LBP associated with psychosocial factors than males. 